\title{
Development and use of synanthropic phytocenoses with complex invasion in Kaluga region
}

\author{
Valeriy A. Burlutskiy ${ }^{1}$, Vladimir N. Mazurov ${ }^{1}$, Ivan E. Osokin ${ }^{2}$, \\ Aleksandr F. Peliy ${ }^{3 *}$, Polina S. Semeshkina ${ }^{1}$, Ekaterina S. Borodina ${ }^{4}$, \\ Murat S. Gins ${ }^{5}$, Aleksey F. Peliy ${ }^{4}$ \\ ${ }^{1}$ Kaluga Research Institute of Agriculture, Kaluga region, Russian Federation \\ ${ }^{2}$ Branch of Rosselkhozcenter on Tver Region, Tver, Russian Federation \\ ${ }^{3}$ Peoples' Friendship University of Russia (RUDN University), \\ Moscow, Russian Federation \\ ${ }^{4}$ Russian State Agrarian University - Moscow Timiryazev Agricultural Academy, \\ Moscow, Russian Federation \\ ${ }^{5}$ Federal Scientific Center of Vegetable Growing, \\ Moscow region, Russian Federation \\ *Corresponding author: kaluga-peliy@yandex.ru
}

\begin{abstract}
Currently, less than 33\% of arable land is used in Meshchovskoye Opolye. Optimizing technology elements of resource-saving development of synanthropic fallow phytocenoses with complex invasion is relevant. The article is devoted to analysis of development of self-organizing phytocenoses with varying invasion degrees and their use on lands temporarily withdrawn from active agricultural use. Field experiments were carried out on postagrogenic gray forest loamy soils in Kaluga Research Institute of Agriculture in 2006-2018. Influence of mineral fertilizers as an optimization element of technology of fallow development was studied using transects and permanent survey sites on the area of $12.0 \mathrm{ha}$. The reasons for change in productivity and its determining elements in hayfields in autogenous - allogenic phytocenoses were analysed. We established that economic value of plant communities was determined by potential of constituent species and variability of their productivity in years with various environmental conditions. 12 years later phytocenoses become homogeneous and consist of 10-12 main plant species, determining green mass productivity by $75 \%$. Compared to native species invasive plant species have $1.4-2.0$ fold higher productivity which accounts for $60 \%$ and more productivity of phytocenoses. Transforming role of Erigeron canadensis L., Lupinus polyphyllus Lindl. and Solidago gigantea Ait. on their expansion into aboriginal herb (share in mowed mass - $40 \%$ or more) communities was shown; their high adaptive potential for ecological-soil conditions of Meshchovskoye Opolye (center of Nonchernozem Zone of Russia) was established. Application of mineral fertilizers $\left(\mathrm{P}_{40} \mathrm{~K}_{90}\right)$ in the secondary Trifolium medium phytocenoses (more than $40 \%$ ) contributed to 2.4-fold increase in its productivity (from 1.38 to $3.29 \mathrm{~kg} / \mathrm{m}^{2}$ ) and increased productivity stability by $60 \%$, reducing low-value species in crop structure by 1.6 times. The total area of cenopopulations increased by $10.4-21.5 \%$, yields — from 2.31 to $4.41 \mathrm{~kg} / \mathrm{m}^{2}$.
\end{abstract}

Keywords: fallow lands, gray forest soils, synanthropic phytocenoses, invasive species, mineral fertilizers, productivity

(c) Burlutskiy V.A., Mazurov V.N., Osokin I.E., Peliy Aleksandr F., Semeshkina P.S., Borodina E.S., Gins M.S., Peliy Aleksey F., 2019.

(c) This work is licensed under a Creative Commons Attribution 4.0 International License https://creativecommons.org/licenses/by/4.0/ 


\section{Introduction}

Opolye is one of the most fertile type of lands in the central region of Russia, $85 \%$ of which was used for agriculture in the second half of the 20th century. Currently, less than $33 \%$ of arable land is used in Meshchovskoye Opolye. The regional government together with the Ministry of Agriculture of the Russian Federation pays special attention to the solution of this issue; however, the efficiency remains low. Some features of development of secondary meadow phytocenoses and their cultivation have been revealed [1-7]. There is an insufficient amount of research on optimization of technology for resource-saving development of synanthropic phytocenoses with complex invasion in Kaluga region.

\section{Materials and methods}

Experiments were conducted on derelict lands with gray forest loamy soils in 2006-2018. Evolution of secondary phytocenoses and developing alternative technologies for accelerated cultivation of fallow lands in Kaluga Research Institute of Agriculture were studied. The monitoring site was located on a gently sloping gulch of floodplain terrace of the Vyssa river within the moderately eroded slope of the southeast exposure. 2 parallel transects were laid at a distance of $50 \mathrm{~m}$ from each other on the area of more than 12.0 ha to study allogeneic series. Each transect had 10 permanent plots with $250 \mathrm{~m}^{2}$ in area which were at a distance of $100 \mathrm{~m}$ from each other. Effect of mineral fertilizers in doses of $\mathrm{P}_{40} \mathrm{~K}_{60}$ and $\mathrm{P}_{40} \mathrm{~K}_{90}$ on productivity and structure of synanthropic phytocenoses was studied.

\section{Results and discussion}

By 2018 phytocenoses had been formed with varying weed invasion level. Initial stages (up to 2-3 years of development) were classified as Stellarietea mediae Tx. et al. Ex von Rochow 1951, and later ones - Artemisietea vulgaris Lohmeyer et al. Ex von Rochow 1951 [8]. The series developed in reserve mode from the bank of diasporas after turf development had a common floristic core with previous phytocenoses and were represented mainly by agrobiological group of motley grasses (55\%). The most common groups consisted of aboriginal and adventitious species in varying quantities. Such transformers as E. canadensis, L. polyphyllus and S. gigantea developed successfully spreading freely throughout the Kaluga region [9]. 12 years later the phytocenoses became homogeneous and consisted of 10-12 main plant species, determining green mass productivity by $75 \%$, and adventitious species — by $35 \%$ (Table 1 ).

The phytocenoses of Indemutatios quarolis were determined by potential of individual plant species during their full vegetative development, and by variability of productivity in years with different environmental conditions. The communities of L. polyphyllus and S. gigantea were less dependent on such influences, while agriophyte E. canadensis contributed to the formation of their expansion boundaries. The highest variability of productivity was observed for indigenous species (average $35.99 \%$ ), ranging from $18.66 \%$ for $C$. epigeios to $56.31 \%$ for $H$. perforatum. Productivity of adventitious species was characterized by lower variation - from $19.83 \%$ in E. canadensis to $22.72 \%$ in S. gigantea. Yields of invasive species significantly 
Cenopopulation structure and characteristics

Table 1 of invasive secondary meadow phytocenosis, June 2014-2018

\begin{tabular}{|l|c|c|c|c|c|}
\hline \multirow{2}{*}{ Species / group } & \multicolumn{3}{c|}{ Productivity, $\mathrm{kg} / \mathrm{m}^{2}$} & \multirow{2}{*}{$W, \%$} \\
\cline { 2 - 5 } & $M \pm m$ & $\max$ & $\min$ & \multirow{2}{*}{$C v, \%$} & \\
\hline Phytocenosis & $2.08 \pm 0.36$ & 2.39 & 1.68 & 34.32 & 100.00 \\
\hline Main components: & $1.74 \pm 0.25$ & 2.01 & 1.42 & 28.81 & 83.84 \\
\hline Calamagrostis epigeios (L.) Roth & $0.39 \pm 0.07$ & 0.43 & 0.33 & 18.66 & 18.54 \\
\hline Erigeron canadensis L. AiN. S-2 & $0.32 \pm 0.03$ & 0.37 & 0.25 & 19.83 & 15.30 \\
\hline Lupinus polyphyllus Lindl. CiN. S-1 & $0.21 \pm 0.02$ & 0.25 & 0.18 & 21.50 & 10.23 \\
\hline Solidago gigantean Ait. ACiN. S-1 & $0.16 \pm 0.02$ & 0.19 & 0.14 & 20.31 & 7.91 \\
\hline Tanacetum vulgare L. & $0.15 \pm 0.02$ & 0.17 & 0.12 & 22.72 & 7.01 \\
\hline Artemisia vulgaris L. & $0.13 \pm 0.02$ & 0.15 & 0.11 & 33.46 & 6.09 \\
\hline Vicia sepium L. & $0.12 \pm 0.02$ & 0.14 & 0.09 & 34.77 & 5.71 \\
\hline Chamerion angustifolium (L.) Holub & $0.11 \pm 0.02$ & 0.13 & 0.08 & 40.87 & 5.08 \\
\hline Hypericum perforatum L. & $0.07 \pm 0.02$ & 0.10 & 0.05 & 56.31 & 3.58 \\
\hline Equisetum arvense L. & $0.06 \pm 0.10$ & 0.07 & 0.04 & 44.65 & 2.70 \\
\hline Potentilla anserine L. & $0.04 \pm 0.01$ & 0.04 & 0.03 & 37.70 & 1.67 \\
\hline
\end{tabular}

Note: A-CiN - Accidental \& Cultivated alien Invasive Naturalization plants; Aliens. str. - invasive naturalized unintentionally and intentionally introduced species, S-1 - invasive status of transformer; S-2 - invasive status of agriophyte, according to Richardson et al. [11]; W, \% - mass fraction in crop structure.

exceeded yields of native plant species. Close dependencies were observed between yields of phytocenoses and productivity of the group with dominant adventitious species $(r=79.54 \pm 0.21)$, area of subpopulations $(r=91.21 \pm 0.18)$, occurrence $(r=87.47 \pm 0.19)$ and stand height $(r=85.15 \pm 0.19)$. Introduction of the advents contributed to the rapid transformation of phytocenoses - reducing species diversity and simplifying phytocenose structure. Higher levels of specific productivity and stability of adventitious species can be considered as a manifestation of their adaptive potential to the ecological and soil conditions of Meshchovskoye Opolye.

The area of the most valuable feed groups of Trifolium medium in the composition of autogenous phytocenoses varied from 7.6 to $17.5 \%$ and averaged $11.0 \%$ per 1 ha of fallow lands in 2015-2018. Top mineral fertilizing contributed to the redistribution of quantitative and qualitative links between the phytocenosis elements [11-16]. Increase in fertilizer rates increased stability of their productivity. Application of $\left(\mathrm{P}_{40} \mathrm{~K}_{90}\right)$ resulted in increase in the total area of $T$. medium cenopopulations by $10.4-21.5 \%$ and yield increased from 2.31 to $4.41 \mathrm{~kg} / \mathrm{m}^{2}$. The specific productivity increased more than 2 times (Table 2).

Using phytocenoses as hayfields in their allogeneic series resulted in significant increase in phytocenotic stability of $T$. medium. The ratio of $T$. medium mass fraction to secondary species in structure of mowed mass increased from 1.5 to 3.0, and coefficient of $T$. medium productivity variation decreased from 61.84 to $38.45 \%$. A close relationship was found between phytocenoses yields and $T$. medium specific productivity $(r=0.82 \pm 0.18)$, its share in the crop structure $(r=0.94 \pm 0.08)$ and stand height $(r=0.57 \pm 0.20)$. Productivity variability of secondary species was not significantly changed. 
Structure and properties of T. medium phytocenoses, 2015-2018

\begin{tabular}{|c|c|c|c|c|c|}
\hline \multirow{2}{*}{ Species / group } & \multicolumn{4}{|c|}{ Productivity, $\mathrm{kg} / \mathrm{m}^{2}$} & \multirow{2}{*}{$W, \%$} \\
\hline & $M \pm m$ & $\max$ & $\min$ & $C v, \%$ & \\
\hline \multicolumn{6}{|c|}{ Natural soil fertility } \\
\hline T. medium L. phytocenosis & $2.31 \pm 0.88$ & 2.46 & 0.60 & 76.42 & 100.00 \\
\hline T. medium L. & $1.38 \pm 0.43$ & 2.33 & 0.58 & 61.84 & 59.65 \\
\hline Secondary species & $0.93 \pm 0.37$ & 2.67 & 0.31 & 79.20 & 40.35 \\
\hline \multicolumn{6}{|c|}{$\mathrm{P}_{40} \mathrm{~K}_{60}$ fertilization } \\
\hline T. medium L. phytocenosis & $3.23 \pm 0.96$ & 4.75 & 0.77 & 59.45 & 100.00 \\
\hline T. medium L. & $2.17 \pm 0.60$ & 3.42 & 0.65 & 57.28 & 67.18 \\
\hline Secondary species & $1.06 \pm 0.45$ & 1.33 & 0.21 & 84.33 & 32.82 \\
\hline \multicolumn{6}{|c|}{$\mathrm{P}_{40} \mathrm{~K}_{90}$ fertilization } \\
\hline T. medium L. phytocenosis & $4.41 \pm 1.01$ & 7.13 & 1.22 & 45.76 & 100.00 \\
\hline T. medium L. & $3.29 \pm 0.63$ & 6.45 & 1.17 & 38.45 & 74.59 \\
\hline Secondary species & $1.12 \pm 0.45$ & 2.69 & 0.38 & 81.06 & 25.41 \\
\hline
\end{tabular}

\section{CONCLUSIONS}

Autogenous phytocenoses were established to be developed from a soil bank of diasporas formed by previous communities; therefore, they had a common floristic core and potential feeding value. Hay productivity was extremely low without the use of elements of surface improvement technology.

It has been revealed that invasive species: Erigeron canadensis L., Lupinus polyphyllus Lindl. and Solidago gigantea Ait. got advantage during grass restoring process under conditions of Meshchovskoye Opolye. The plants gave the impression of being aboriginal and constituted more than $1 / 3$ of mowed mass.

Application of mineral fertilizers $\left(\mathrm{P}_{40} \mathrm{~K}_{90}\right)$ in secondary Trifolium medium phytocenoses resulted in 1.9-fold increase in vegetative mass, 2-fold increase in T. medium specific productivity and 1.6-fold reduction of low-value species in crop structure.

\section{REFERENCES}

1. Akhromeev LM. Nature, Genesis, Development History and Landscape Structure of the Opolees in Central Russia. Bryansk: Bryansk State University Publ.; 2008. (In Russ).

2. Savich VI, Sychev VG, Zamaraev AG, Syunyaev NK, Nikolskii YN. Energy assessment of soil fertility. Moscow: VNIIA Publ.; 2007. (In Russ).

3. Mazurov VN, Burlutsky V., Semeshkina PS, Zavalin AA. The phytocenoses productivity and stability on the temporary withdrawal land from agriculture. Vestnik of the Russian agricultural science. 2017; (2):9-11. (In Russ).

4. Baranov SG, Bibik TS, Vinokurov IY. Testing stability of wheat development in agrophytocenoses of Vladimirsky Opolye. Advances in current natural sciences. 2018; (12-2):272-276. (In Russ).

5. Ustyuzhanina OA, Sokolova LA, Golofteeva AS, Burlutskiy VA. The effect of different mineral backgrounds on the crop yield and the coefficient of fluctuating asymmetry for the winter and spring wheat. Regional Environmental Issues. 2017; (3):99-102. (In Russ).

6. Kutuzova AA, Privalova KN, Teberdiev DM, Semenov NA, Raev AP, Lebedev DN. Method of effective development of multi-age deposits based on multivariate technologies for pastures 
and hayfields and sequence of their return to arable land in the Non-Black Earth Zone of the Russian Federation. Moscow: Ugreshskaya tipografiya Publ.; 2017. (In Russ).

7. Dorogova YA, Zhukova LA, Turmuhametova NV, Polyanskaya TA, Notov AA, Dementyeva SM. Methods of Analysis of Environmental Diversity of Plants. Biology and Medicine. 2016; 8(7):354. Available from: doi: 10.4172/0974-8369.1000354.

8. Ermakov NB. Prodromus of higher vegetation units in Russia. In: Mirkin BM, Naumova LG. (eds.) The current state of the basic vegetation science concepts. Ufa: AN RB Gilem Publ.; 2012. p. 377-483. (In Russ).

9. Reshetnikova NM, Maiorov SR, Skvortsov AK, Krylov AV, Voronkina NV, Popchenko MI, et al. Kaluga flora: an annotated list of vascular plants of the Kaluga region. Moscow: KMK Publ.; 2010. (In Russ).

10. Richardson DM, Pyšek P, Rejmánek M, Barbour MG, Panetta FD, West CJ. Naturalization and invasion of alien plants: concepts and definitions. Diversity and distributions. 2000; 6(2):93-107. Available from: doi: 10.1046/j.1472-4642.2000.00083.x.

11. Mazurov VN, Semeshkina PS, Filonenko VA, Lukashov VN. Spring field practices in Kaluga region in 2019 (guide). Kaluga: Kaluga Research Institute of Agriculture Publ.; 2019. (In Russ).

12. Platonova SY, Peliy AF, Gins EM, Sobolev RV, Vvedensky VV. The study of morphological and biochemical parametres of Amaranthus tricolor L. Valentina variety. RUDN Journal of Agronomy and Animal Industries. 2018; 13(1):7-13. (In Russ). Available from: doi: 10.22363/2312-797X-2018-13-1-7-13.

13. Peliy AF, Diop A, Borodina ES, Burlutskiy VA, Vvedenskaya AV, Vvedenskiy VV, et al. Use of Amazone precision sprayer in rape seed cultivation technology. In: Plyushchikov VG, Dokukin PA. (eds.) Innovation in Agriculture. Conference Papers of the X international Scientific and Practical Conference, 26-28 April 2018, Moscow, Russia. Moscow: RUDN Publ.; 2018. p. $18-21$.

14. Vvedenskaya AV, Vvedenskiy VV, Khorokhorov AM, Gins MS. Nondestructive methods of diagnostics of nitrogen provision of plants by optoelectronic system of plants monitoring. RUDN Journal of Agronomy and Animal Industries. 2017; 12(1):7-16. (In Russ). Available from: doi: 10.22363/2312-797X-2017-12-1-7-16.

15. Garnier E, Navas ML, Grigulis K. Plant Functional Diversity: Organism traits, community structure, and ecosystem properties. Oxford: Oxford University Press; 2016.

16. Barthélémy D, Caraglio Y. Plant architecture: a dynamic, multilevel and comprehensive approach to plant form, structure and ontogeny. Annals of botany. 2007; 99(3):375—407. Available from: doi: org/10.1093/aob/mcl260.

\title{
Article history:
}

Received: 29 April 2019

Accepted: 30 May 2019

\begin{abstract}
About authors:
Burlutskiy Valeriy Anatolyevich - Candidate of Sciences in Agriculture, Leading Researcher, Kaluga Research Institute of Agriculture; 2, Tsentral'naya st., Kaluzhskaya opytnaya sel'skokhozyaystvennaya stantsiya Village., Peremyshl District, Kaluga Region, 249142, Russian Federation; e-mail: v.burlutsky@yandex.ru

Mazurov Vladimir Nikolaevich - Candidate of Sciences in Agriculture, Director of Kaluga Research Institute of Agriculture; 2, Tsentral'naya st., Kaluzhskaya opytnaya sel'skokhozyaystvennaya stantsiya Village, Peremyshl District, Kaluga Region, 249142, Russian Federation; e-mail: v.mazurov@kniish.org
\end{abstract}

Osokin Ivan Evgenievich - Head of the Branch of Rosselkhozcenter on Tver Region, 9 Ozernaya st., Tver, 170008, Russian Federation, e-mail: ivoc@yandex.ru 
Peliy Aleksandr Fedorovich - Postgraduate student, Agrobiotechnological Department, Agrarian and Technological Institute, RUDN University; 6, Miklukho-Maklaya st., Moscow, 117198, Russian Federation; e-mail: kaluga-peliy@yandex.ru

Semeshkina Polina Sergeevna - Candidate of Sciences in Agriculture, Deputy Director for Research, Kaluga Research Institute of Agriculture; 2, Tsentral'naya st., Kaluzhskaya opytnaya sel'skokhozyaystvennaya stantsiya Village, Peremyshl District, Kaluga Region, Russian Federation, 249142; e-mail: p.semeshkina@kniish.org

Borodina Ekaterina Sergeevna - Postgraduate student, Department of Plant Growing and Meadow Ecosystems, Russian State Agrarian University — Moscow Timiryazev Agricultural Academy; 49, Timiryazevskaya st., Moscow, 127550, Russian Federation; e-mail: ekaterinapeliy@yandex.ru Gins Murat Sabirovich - Doctor of Sciences in Biology, Chief of the Laboratory of Plant Physiology, Biochemistry, Introduction and Functional Products, Federal Scientific Center of Vegetable Growing; 14, Selektsionnaya st., VNIISSOK Village, Odintsovo District, Moscow Region, 143080, Russian Federation; e-mail: anirr@bk.ru

Peliy Aleksey Fedorovich - Master student, Russian State Agrarian University - Moscow Timiryazev Agricultural Academy; 49, Timiryazevskaya st., Moscow, 127550, Russian Federation

\title{
For citation:
}

Burlutskiy VA, Mazurov VN, Osokin I.E., Peliy AF, Semeshkina PS, Borodina ES, Gins MS, Peliy AF. Development and use of synanthropic phytocenoses with complex invasion in Kaluga region. RUDN Journal of Agronomy and Animal Industries. 2019; 14(2):114-122. doi: 10.22363/2312-797X-2019-14-2-114-122.

\section{Особенности развития и использования синатропных фитоценозов с комплексной инвазией в условиях Калужской области}

\author{
В.А. Бурлуцкий ${ }^{1}$, В.Н. Мазуров ${ }^{1}$, И.Е. Осокин ${ }^{2}$, \\ А.Ф. Пэлий ${ }^{3 *}$, П.С. Семешкина ${ }^{1}$, Е.С. Бородина ${ }^{4}$, \\ М.С. Гинс ${ }^{5}$, А.Ф. Пэлий ${ }^{4}$ \\ ${ }^{1}$ Калужский научно-исследовательский институт сельского хозяйства, \\ Калужская область, Российская Федерация \\ ${ }^{2}$ Филиал ФГБУ «Россельхозцентр» по Тверской области, Тверь, Российская Федерация \\ ${ }^{3}$ Российский университет дружбы народов, Москва, Российская Федерация \\ ${ }^{4}$ РГАУ-МСХА имени К.А. Тимирязева, Москва, Российская Федерация \\ ${ }^{5}$ Федеральный научный центр овощеводства, \\ Московская обл., Российская Федерация \\ *kaluga-peliy@yandex.ru
}

Аннотация. В настоящее время в Мещовском ополье не используется более 33\% пашни. Вопрос оптимизации элементов технологии ресурсосберегающего освоения синантропных фитоценозов залежей с комплексной инвазией является открытым. Статья посвящена актуальной научнопроизводственной задаче - анализа и динамики развития самоорганизующихся фитоценозов 
с различной степенью инвазии и их использованию на землях, временно выведенных из активного сельскохозяйственного оборота. В Калужском НИИСХ в полевом опыте на постагрогенных серых лесных среднесуглинистых почвах в 2006-2018 гг. изучали влияние минеральных удобрений как элемента оптимизации технологии освоения разновозрастных залежей методом трансекты и постоянных учетных площадок на площади 12,0 га. Дан анализ причин изменения продуктивности определяющих ее элементов при одноукосном сенокосном использовании в ряду: автогенные - аллогенные фитоценозы. Установлено, что хозяйственная ценность ценозов определяется потенциалом составляющих видовой вариабельностью их продуктивности в различные по степени напряженности экологических условий годы. Фитоценозы на 12-й год развития являются гомогенными и состоят из 10-12 основных видов, которые на 75\% формируют укосную массу. Уровень продуктивности инвазионных видов в 1,4-2,0 раза превышает уровень аборигенных и обусловливает на $60 \%$ и более продуктивность фитоценозов. Показана трансформирующая роль Erigeron canadensis L., Lupinus polyphyllus Lindl. и Solidago gigantea при их экспансии в аборигенные разнотравные (доля в укосной массе - 40\% и более) сообщества, и установлен их высокий адаптивный потенциал к экологопочвенным условиям Мещовского ополья Центра Нечерноземной зоны России. Площадь наиболее ценных в кормовом отношении группировок Trifolium medium L. изменялась в пределах от 7,6 до $17,5 \%$ и в среднем составила $11,0 \%$ на 1 га залежи. Таким образом, внесение минеральных удобрений $\left(\mathrm{P}_{40} \mathrm{~K}_{90}\right)$ во вторичных фитоценозах с преимущественным участием T. medium (более 40\%) способствовало повышению его удельной продуктивности в 2,4 раза (с 1,38 до 3,29 кг/м²) и уровня стабильности продуктивности на $60 \%$, а также снижению доли участия малоценных видов в структуре урожая в 1,6 раза. Общая площадь ценопопуляций возросла на 10,4-21,5 \%, урожайность с 2,31 до $4,41 \mathrm{\kappa г/ \textrm {M } ^ { 2 }}$.

Ключевые слова: залежные земли, серые лесные почвы, синантропные фитоценозы, инвазионные виды, минеральные удобрения, продуктивность

\section{БИБЛИОГРАФИЧЕСКИЙ СПИСОК}

1. Ахромеев Л.М. Природа, генезис, история развития и ландшафтная структура ополий Центральной России. Брянск: РИО Брянского государственного университета, 2008. $182 \mathrm{c}$.

2. Савич В.И., Сычев В.Г., Замараев А.Г., Сюняев Н.К., Никольский Ю.Н. Энергетическая оценка плодородия почв. М.: ВНИИА, 2007. 520 с.

3. Мазуров В.Н., Бурлуцкий В.А., Семешкина П.С., Завалин А.А. Продуктивность и устойчивость фитоценозов на временно выбывших из оборота землях // Вестник Российской сельскохозяйственной науки. 2017. № 2. С. 9-11.

4. Баранов С.Г., Бибик Т.С., Винокуров И.Ю. Опыт тестирования стабильности развития пшеницы в агрофитоценозах Владимирского ополья // Успехи современного естествознания. 2018. № 12-2. С. 272-276.

5. Устюжанина О.А., Соколова Л.А., Голофтеева А.С., Бурлуцкий В.А. Влияние разных минеральных фонов на урожайность и коэффициент флуктуирующей асимметрии для озимой и яровой пшениц // Проблемы региональной экологии. 2017. № 3. С. 99-102.

6. Кутузова А.А., Привалова К.Н., Тебердиев Д.М., Семенов Н.А., Раев А.П., Лебедев Д.Н. и др. Методика эффективного освоения разновозрастных залежей на основе многовариантных технологий под пастбища и сенокосы и очередности возврата их в пашню в Нечерноземной зоне РФ / ФГБНУ «ВНИИ кормов им. В.Р. Вильямса». М.: ООО «Угрешская типография», 2017. 64 с.

7. Dorogova Y.A., Zhukova L.A., Turmuhametova N.V., Polyanskaya T.A., Notov A.A., Dementyeva S.M. Methods of Analysis of Environmental Diversity of Plants // Biology and Medicine. 2016. Vol. 8. № 7. P. 354. doi: 10.4172/0974-8369.1000354.

8. Ермаков Н.Б., Миркин Б.М., Наумова Л.Г. Продромус высших единиц растительности России // Современное состояние основных концепций науки о растительности. УФА: АН РБ Гилем, 2012. С. 377—483. 
9. Решетникова Н.М., Майоров С.Р., Скворцов А.К. Крылов А.В., Воронкина Н.В., Попченко М.И. и др. Калужская флора: аннотированный список сосудистых растений Калужской области. М.: Т-во научных изданий КМК, 2010. 548 с.

10. Richardson D.M., Pyšek P., Rejmánek M., Barbour M.G., Panetta F.D., West C.J. Naturalization and invasion of alien plants: concepts and definitions // Diversity and distributions. 2000. Vol. 6. № 2. P. 93-107. doi: 10.1046/j.1472-4642.2000.00083.x.

11. Мазуров В.Н., Семешкина П.С., Филоненко В.А., Лукашов В.Н. и др. Особенности проведения весенне-полевых работ в Калужской области в 2019 году (руководство). Калуга: Калужский научно-исследовательский институт сельского хозяйства, 2019. 36 с.

12. Платонова С.Ю., Пэлий А.Ф., Гинс Е.М., Соболев Р.В., Введенский В.В. Изучение морфологических и биохимических показателей растений Amaranthus tricolor L. сорта Валентина // Вестник Российского университета дружбы народов. Серия: Агрономия и животноводство. 2018. Т. 13. № 1. С. 7-13. doi 10.22363/2312-797X-2018-13-1-7-13.

13. Peliy A.F., Diop A., Borodina E.S., Burlutskiy V.A., Vvedenskaya A.V., Vvedenskiy V.V., et al. Use of Amazone precision sprayer in rape seed cultivation technology // Инновационные процессы в сельском хозяйстве : сборник статей X Международной научно-практической конференции / под ред. В.Г. Плющикова, П.А. Докукина. М.: Российский университет дружбы народов, 2018. С. 18-21.

14. Введенская А.В., Введенский В.В., Гинс М.С., Хорохоров А.М. Недеструктивный метод диагностики азотообеспеченности растений оптико-электронной системой мониторинга растений // Вестник Российского университета дружбы народов. Серия: Агрономия и животноводство. 2017. Т. 12. № 1. С. 7-16. doi: 10.22363/2312-797X-2017-12-1-7-16.

15. Garnier E., Navas M.L., Grigulis K. Plant Functional Diversity: Organism traits, community structure, and ecosystem properties. Oxford: Oxford University Press, 2016. 231 p.

16. Barthélémy D., Caraglio Y. Plant architecture: a dynamic, multilevel and comprehensive approach to plant form, structure and ontogeny // Annals of botany. 2007. Vol. 99. № 3. P. $375-407$.

\section{История статьи:}

Поступила в редакцию: 29 апреля 2019 г. Принята к публикации: 30 мая 2019 г.

\section{Об авторах:}

Бурлуцкий Валерий Анатольевич - кандидат сельскохозяйственных наук, ведущий научный сотрудник, Калужский НИИСХ; Российская Федерация, Калужская область, Перемышльский район, 249142, с. Калужская опытная сельскохозяйственная станция, ул. Центральная, д. 2, e-mail: v.burlutsky@yandex.ru

Мазуров Владимир Николаевич - кандидат сельскохозяйственных наук, директор, Калужский НИИСХ; Российская Федерация, Калужская область, Перемышльский район, 249142, c. Калужская опытная сельскохозяйственная станция, ул. Центральная, д. 2, e-mail: v.mazurov@kniish.org

Осокин Иван Евгеньевич - руководитель филиала ФГБУ «Россельхозцентр» по Тверской области, Российская Федерация, 170008, г. Тверь, ул. Озерная, д. 9, e-mail: ivoc@yandex.ru

Пэлий Александр Федорович - аспирант, агробиотехнологический департамент, Аграрнотехнологический институт, Российский университет дружбы народов; Российская Федерация, 117198, Москва, ул. Миклухо-Маклая, 6, e-mail: kaluga-peliy@yandex.ru

Семешкина Полина Сергеевна - кандидат сельскохозяйственных наук, заместитель директора по научной работе, Калужский НИИСХ; Российская Федерация, Калужская область, Перемышльский район, 249142, с. Калужская опытная сельскохозяйственная станция, ул. Центральная, д. 2, e-mail: p.semeshkina@kniish.org 
Бородина Екатерина Сергеевна - аспирант кафедры растениеводства и луговых экосистем, Российский государственный аграрный университет - Московская сельскохозяйственная академия им. Тимирязева; Российская Федерация, 127550, г. Москва, ул. Тимирязевская, д. 49, e-mail: ekaterinapeliy@yandex.ru

Гинс Мурат Сабирович - доктор биологических наук, заведующий лабораторией физиологии и биохимии растений, интродукции и функциональных продуктов; Федеральный научный центр овощеводства; Российская Федерация, 143080, Московская обл., Одинцовский район, поселок ВНИИССОК, ул. Селекционная, д. 14, e-mail: anirr@bk.ru

Пэлий Алексей Федорович - магистр, Российский государственный аграрный университет Московская сельскохозяйственная академия им. Тимирязева, 127550, г. Москва, ул. Тимирязевская, д. 49; e-mail: kaluga-peliy@yandex.ru

\section{Для цитирования:}

Burlutsky V.A., Mazurov V.N., Osokin I.E., Peliy A.F., Semeshkina P.S., Borodina E.S., Gins M.S., Peliy A.F. Development and use of synanthropic phytocenoses with complex invasion in Kaluga region // Вестник Российского университета дружбы народов. Серия: Агрономия и животноводство. 2019. Т. 14. № 2. С. 114-122. doi: 10.22363/2312-797X-2019-14-2-114-122. 